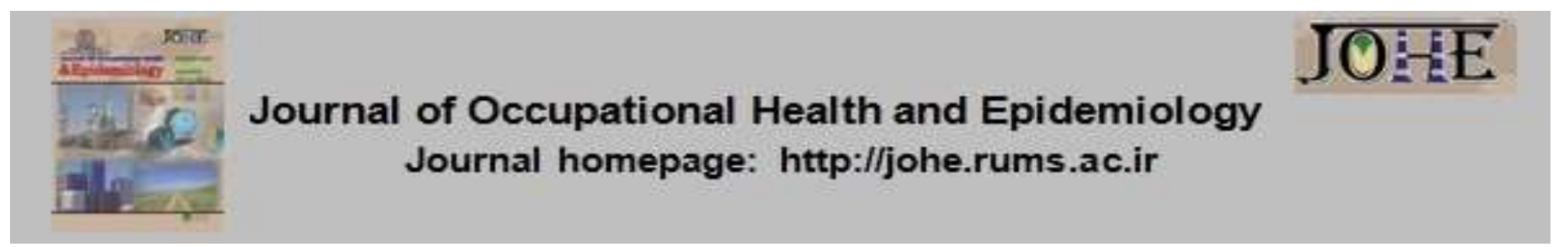

\title{
Factors contributing to fatal road traffic accidents in the South of Kerman during the period from 2013 to 2017 , Iran
}

\author{
Naser Nasiri ${ }^{1}$, Parvaneh Nazari², Ali Kamali ${ }^{3}$, Ali Sharifi ${ }^{4}$, Hamid Sharifi $5^{*}$ \\ 1. MSc of Epidemiology, Department of Public Health, School of Public Health, Jiroft University of Medical Sciences, Jiroft, Iran. \\ 2. MSc Student of Nursing, Department of Nursing, School of Nursing, Jiroft University of Medical Sciences, Jiroft, Iran. \\ 3. Assistant Prof., Department of Infection Diseases, School of Medicine, Jiroft University of Medical Sciences, Jiroft, Iran. \\ 4. Associate Prof., Department of Ophthalmology, Afzalipour School of Medicine, Kerman University of Medical Sciences, Kerman, \\ Iran. \\ 5. Associate Prof., HIV/STI Surveillance Research Center, WHO Collaborating Center for HIV Surveillance, Institute for Futures \\ Studies in Health, Kerman University of Medical Sciences, Kerman, Iran.
}

Citation: Nasiri N, Nazari P, Kamali A, Sharifi A, Sharifi H. Factors contributing to fatal road
traffic accidents in the South of Kerman during the period from 2013 to 2017, Iran. JOHE.
$2019 ; 8(1): 6-11$.

Article Info
* Corresponding author:
Hamid Sharifi,
E-mail:
Sharifihami@gmail.com
Article history
Received: Sep, 2018
Accepted: Jan, 2019
doi 10.29252/johe.8.1.6
Print ISSN: 2251-8096
Online ISSN: 2252-0902
Peer review under
responsibility of Journal of
Occupational Health and
Epidemiology

\begin{abstract}
Background: Several factors influence the growth in the number of road traffic accidents and the resulting death rate. Road accident scenarios can be considered in different seasons and time intervals. In the present study, the role of factors effective in the growth of the number of accidents was explored in the south of Kerman during the period from 2013 to 2017.

Materials and Methods: In this cross-sectional study, the data were collected from the Traffic Police Unit's database in the south of Kerman during the period from 2013 to 2017. The data obtained included the time of the day, roads of accidents, numbers of fatal accidents, and years of occurrence. The data were analysed using the logistic regression. Results: After examining the role of various factors in fatal road traffic accidents, it became clear that the chances of death were higher in road accidents on main roads ( $O R=1.30$; $95 \% \mathrm{Cl}=1.02-1.70 ; \mathrm{p}=0.037$ ) than on rural roads. In terms of the seasons of occurrence, death rates were higher in autumn $(\mathrm{OR}=1.30 ; 95 \% \mathrm{Cl}=1.02-1.80 ; \mathrm{p}=0.027)$ than in winter. From among the effective factors, overspeed $(\mathrm{OR}=1.90 ; 95 \% \mathrm{Cl}=1.40-2.50 ; \mathrm{p}<0.001)$ and deviation to the left lane $(\mathrm{OR}=2.20 ; 95 \% \mathrm{Cl}=1.70-2.90 ; \mathrm{p}$-value $<0.001)$ were more likely to lead to death than drowsiness and inattention to the front.

Conclusion: The results showed that overspeed, deviation to the left lane, as well as accidents on main roads, and in autumn resulted in an increase in the mortality rate. The severity of road accidents would probably decrease in the region by paying more attention to main roads especially in autumn and training drivers.
\end{abstract}

Keywords: Traffic, Accidents, Injuries, Death.

\section{Introduction}

Road traffic accidents are from among the major causes of deaths worldwide (1). Every year, over 1.2 million people die from road accidents. Ninety percent of road traffic deaths occur in low-income and middle-income countries (2). Developing countries with rapid economic growth and a significant increase in the number of motor vehicles have been faced with increased mortality rates and the following burden of injuries caused by road traffic accidents (3).

Iran is one of the countries with a high mortality rate in the Eastern Mediterranean and has the highest rate of road traffic accidents among the countries of this region (4). Road traffic accidents are the second leading cause of deaths in Iran (5). According to a report by the WHO, 24,896 death incidents (32.1 per 100,000 population) in Iran were due to road traffic accidents in 2015 (6). The standardized death 
rate in Iran is twice the global average rate. Statistics show that in Iran, one out of 200 men dies in road traffic accidents (5).

Various factors, such as the level of education, time interval, and personal factors can influence the accident rate (7). Bad behaviours lead to the severity of driving accidents, thereby increasing their probability $(8,9)$. Time intervals, including seasons, months, weeks and days can increase the probability of road accidents (9). In addition, death rates in road accidents vary in different 24-hour conditions (1). The ambient light and weather conditions influence significantly the severity of damage and road traffic deaths (10). The low vision of drivers due to the ambient light causes road traffic deaths and injuries (7). In addition, seasons play a role in road traffic accidents. Identifying the possibilities of vehicle accidents in different seasons and weather conditions will help the health system control road traffic accidents (11).

Environmental conditions, like rainy weathers and road conditions, such as lighting and design styles, as well as slippery roads are effective in road accidents (12).

Over speed, especially in bad weather conditions, increases the death rate (13). There are several factors that affect the relationship between road accidents and vehicles' speed, such as the speed increase on different roads, including rural and urban roads, thereby making the rates of road accidents be varied (14).

Various factors have been reported to cause fatal accidents. Studies show that most fatalities happen during twilight hours (1). Assessing accident-related factors, such as time intervals, including days, months, and seasons can be effective in reducing road accidents (1). The present study was conducted to investigate factors contributing to fatal road traffic accidents in the south of Kerman during the period from 2013 to 2017.

\section{Materials and Methods}

In this cross-sectional study, all road traffic accidents in the south of Kerman were surveyed during the period from March 2013 to March 2017. Southern Kerman has an area of about 43,000 km2, including the seven cities of Jiroft, Anbarabad, Kahnuj, Faryab, Manujan, Qaleh Ganj, Rudbar-e Jonubi, with the population of 800,000 (15). The research data were those recorded by the Traffic Police Unit about road traffic accidents leading to deaths or damage. The data collection tool in this study included the traffic police data records as well as the information obtained from the south Kerman Traffic Police Headquarters. The information included time intervals, (hours, day times, night times, week days, months, seasons, and years of accidents), types of accidents (deaths or injuries), human factors, types of accidents (hitting a vehicle or rollover accidents), types of roads (urban roads, out-of-urban roads, or byways), and drivers' levels of education. Raw data were entered into Stata (windows version 12) for analysis. The entire information was reviewed and coded to be entered into the software. The study was approved by the ethical committee of Jiroft University of Medical Sciences under the ethical code 'IR.JMU.REC.1397.009'.

For data analysis, the logistic regression was utilized. In order to perform the logistic regression analysis, the type of incident was defined as a twoway dependent variable, with the code number 1 assigned to death and 0 to injuries. Variables, such as the type of accidents, drivers' level of education, season, type of road, cause of accident, year of accident, and occurrence on a holiday or other days, were all considered as independent variables. The multivariate logistic regression analysis was performed for the variables with their $p$ values lower than or equal to 0.25 in the univariate analysis and in each step. Variables with the highest significance levels were eliminated from the model using the backward method. The final model was selected with the highest values for the AIC (the Akaike information criterion) and the BIC (the Bayesian information criterion). Data analysis was performed at the significance level of 0.05 , using statistical software Stata 12.

\section{Results}

In total, 2,126 accidents had occurred during the period from 2013 to 2017. In addition, 1,530 accidents $(72.14 \%)$ led to injuries, and there were $591(27.81 \%)$ fatal accidents from 2013 to 2017. The number of accidents leading to injuries were $149(9.74 \%)$ in March, with 112 cases of accidents $(11.51 \%)$ having occurred in July and November. The highest and lowest numbers of fatalities occurred in September $(68,11.51 \%)$ and March (30, $5.08 \%$ ), respectively.

From among week days, the highest and lowest numbers of road traffic accidents occurred on Thursdays $(259,17.35 \%)$ and Saturdays (200, $13.4 \%$, respectively. In addition, the highest and lowest numbers of fatal accidents occurred on Tuesdays (92, 16\%) and Sundays (62, 10.78\%), respectively.

The highest number of accidents leading to injures (381, 27.95\%) occurred within the time interval between 04:00 pm and 07:59 pm; in contrast, the lowest number $(113,8.29 \%)$ of such accidents occurred after midnight until 5:59 am. In addition, 
the highest number of fatal accidents $(131,26.79 \%)$ occurred within the time interval of between 08:00 pm and 12:00 pm, and the lowest number of fatal accidents occurred from midnight to 5:59 am (53, 10.84\%) (Table 1).

Table 1: The frequency of accidents leading to injuries or deaths based on various causes in 2,126 accidents in the south of Kerman during the period from 2013 to 2017

\begin{tabular}{|c|c|c|c|}
\hline Variable & & $\begin{array}{l}\text { Number (percent) of accidents } \\
\text { leading to injuries }\end{array}$ & $\begin{array}{c}\text { Number (percent) of fatal } \\
\text { accidents }\end{array}$ \\
\hline \multirow{12}{*}{ Month } & March & $122(7.97)$ & $50(8.46)$ \\
\hline & April & 133(8.69) & $49(8.29)$ \\
\hline & May & $119(7.78)$ & $51(8.63)$ \\
\hline & Jun & $112(7.32)$ & $35(5.92)$ \\
\hline & July & $122(7.97)$ & $39(6.60)$ \\
\hline & August & $129(8.43)$ & $68(11.51)$ \\
\hline & September & 143(9.35) & $51(8.63)$ \\
\hline & October & 134(8.76) & $59(9.98)$ \\
\hline & November & 112(7.32) & $58(9.81)$ \\
\hline & December & $131(8.56)$ & $56(9.48)$ \\
\hline & January & $124(8.1)$ & $45(7.61)$ \\
\hline & February & 149(9.74) & $30(5.08)$ \\
\hline \multirow{7}{*}{ Week days } & Saturday & $200(13.4)$ & $90(15.65)$ \\
\hline & Sunday & $204(13.66)$ & $62(10.78)$ \\
\hline & Monday & $202(13.53)$ & 77(13.39) \\
\hline & Tuesday & $216(14.47)$ & $92(16)$ \\
\hline & Wednesday & $209(14)$ & $80(13.91)$ \\
\hline & Thursday & $259(17.35)$ & 14.61))84 \\
\hline & Friday & $203(13.60)$ & $90(15.65)$ \\
\hline \multirow{5}{*}{ Time } & 00:00-05:59 & $113(8.29)$ & $53(10.84)$ \\
\hline & $06: 00-11: 59$ & $268(19.66)$ & $102(20.86)$ \\
\hline & 12:00-15:59 & $247(18.12)$ & $79(16.16)$ \\
\hline & $16: 00-19: 59$ & $381(27.95)$ & $124(25.36)$ \\
\hline & 20:00-23:59 & $354(25.97)$ & 131(26.79) \\
\hline
\end{tabular}

According to figure 1, there has been an increase in the number of incidents leading to injuries from 2013 to 2016, with this trend having decreased in
2017. In addition, despite the significant decrease in the number of incidents leading to injuries in 2017 , the number of deaths increased in this year.

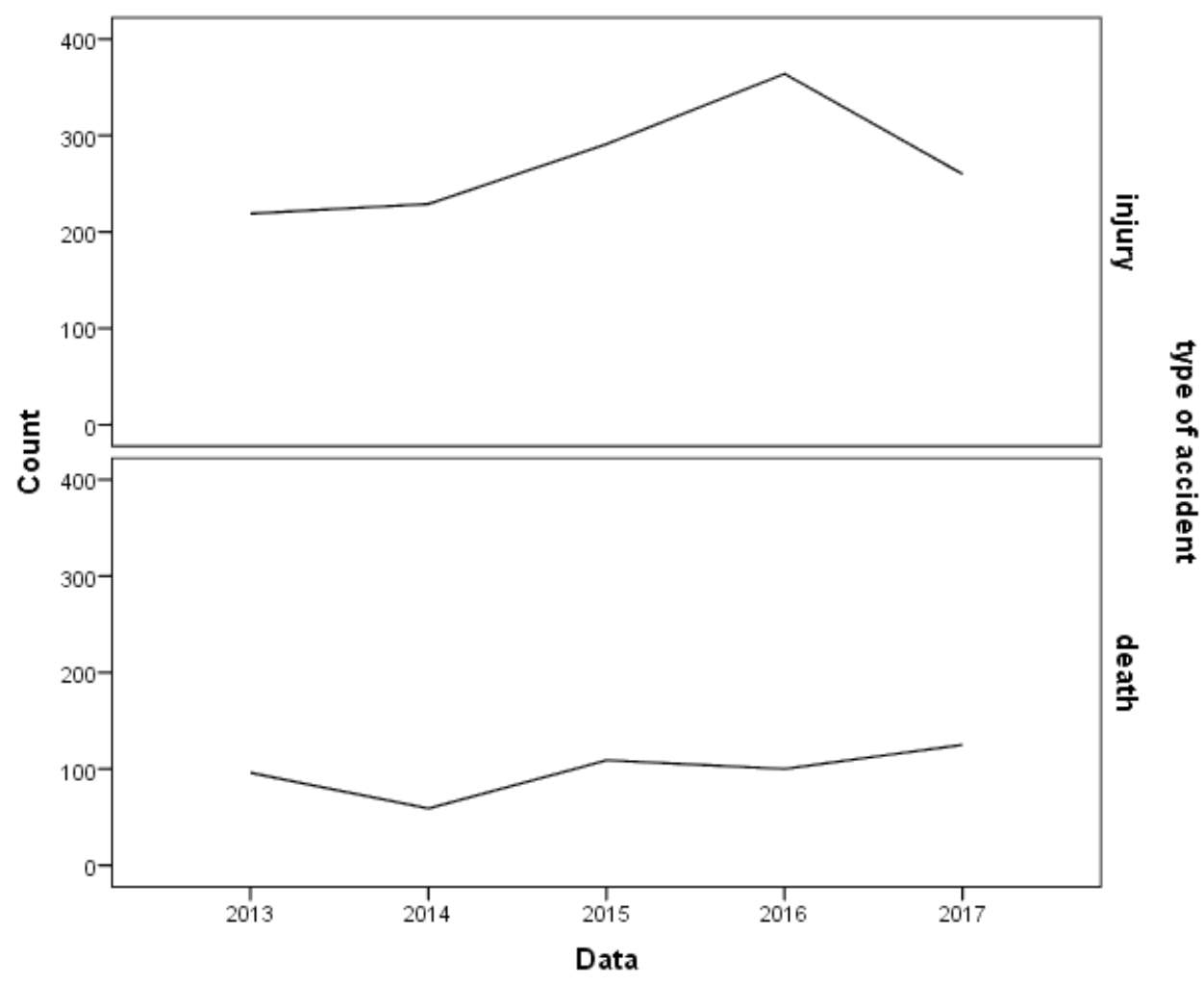

Figure 1: Deaths and injuries caused by road traffic accidents during the period from 2013 to 2017 in the south of Kerman $(n=2,126)$ 
Upon investigating the role of various factors in fatal road traffic accidents using univariable and multivariable regression analyses, we found out that the odds ratio of fatal road traffic accidents on main roads was higher in the univariable $(O R=1.40 ; 95 \%$ $\mathrm{Cl}$ : $1.04-1.80 ; p=0.019$ ) and also the odds ratio of fetal road traffic accident on main road in multivariable model was higher than rural roads (OR $=1.30 ; 95 \% \mathrm{Cl}=1.02-1.70 ; \mathrm{p}=0.037)$. The odds ratio of fatal accidents in autumn (OR $=1.30 ; 95 \%$ $\mathrm{Cl}=1.02-1.70 ; \mathrm{p}=0.039)$ in the univariable and (OR $=1.30 ; 95 \% \mathrm{Cl}=1.02-1.80 ; \mathrm{p}=0.027$ ) multivariable models was by $30 \%$ higher than that of winter. A significant correlation was observed between fatal accidents and the factors of overspeed and deviation to the left lane. From among the factors leading to accidents, the odds ratio of fatality was more in overspeed $(\mathrm{OR}=1.80 ; 95 \% \mathrm{Cl}=1.40-2.30$; $\mathrm{p}<0.001)$ in the univariable and $(\mathrm{OR}=1.90 ; 95 \% \mathrm{Cl}$ $=1.40-2.50 ; p<0.001)$ multivariable models, as well as deviation to the left lane $(\mathrm{OR}=2.10 ; 95 \% \mathrm{Cl}=$ $1.70-2.70 ; \mathrm{p}<0.001)$ in the univariable and $(\mathrm{OR}=$ $2.20 ; 95 \% \mathrm{Cl}=1.70-2.90 ; \mathrm{p}<0.001)$ multivariable models than drowsy driving and inattention to the front (Table 2).

Table 2: The prediction of factors contributing to fatal accidents in 2126 in the south of Kerman during the period from 2013 to 1017

\begin{tabular}{|c|c|c|c|c|c|c|c|c|c|}
\hline Variable & & $\begin{array}{l}\text { Number } \\
\text { of injuries }\end{array}$ & $\begin{array}{l}\text { Number of } \\
\text { deaths }\end{array}$ & $\begin{array}{l}\text { Unadju } \\
\text { sted OR }\end{array}$ & $\begin{array}{c}\text { Confidenc } \\
\text { e interval } \\
95 \%\end{array}$ & $\begin{array}{c}\mathrm{P}- \\
\text { value }\end{array}$ & $\begin{array}{c}\text { OR } \\
\text { Adjust } \\
\text { ment }\end{array}$ & $\begin{array}{c}\text { Confiden } \\
\text { ce } \\
\text { interval } \\
95 \%\end{array}$ & $\begin{array}{c}\mathrm{P}- \\
\text { value }\end{array}$ \\
\hline \multirow[t]{2}{*}{ Education } & $\begin{array}{l}\text { Higher than } \\
\text { high school } \\
\text { diploma }\end{array}$ & $122(45.69)$ & $70(47.62)$ & 1 & & & & & \\
\hline & $\begin{array}{l}\text { Lower than high } \\
\text { school diploma }\end{array}$ & $83(31.09)$ & 47(36.15) & 1.01 & $0.6-1.6$ & 0.896 & & & \\
\hline \multirow{2}{*}{$\begin{array}{l}\text { Types of } \\
\text { accidents }\end{array}$} & $\begin{array}{l}\text { Types of } \\
\text { collisions }\end{array}$ & $959(72.98)$ & $355(27.02)$ & 1 & & & 1 & & \\
\hline & Rollover & $555(71.25)$ & $224(28.75)$ & 1.09 & $0.9-1.3$ & 0.364 & 0.95 & $0.72-1.25$ & 0.667 \\
\hline \multirow{3}{*}{$\begin{array}{l}\text { Types of } \\
\text { roads }\end{array}$} & Rural roads & $250(74.85)$ & $84(25.18)$ & 1 & & & 1 & & \\
\hline & Byways & $501(78.16)$ & $140(21.84)$ & 0.83 & $0.6-1.1$ & 0.242 & 0.78 & $0.6-1.07$ & 0.144 \\
\hline & Main roads & 778(68.31) & $361(31.69)$ & 1.4 & $1.04-1.8$ & 0.019 & 1.3 & $1.02-1.7$ & 0.037 \\
\hline \multirow{4}{*}{ Seasons } & Spring & $374(71.37)$ & $150(28.63)$ & 1.24 & $0.94-1.6$ & 0.133 & 1.2 & $0.9-1.6$ & 0.182 \\
\hline & Summer & $363(71.88)$ & 142(28.12) & 1.2 & $0.9-1.6$ & 0.184 & 1.14 & $0.9-1.5$ & 0.272 \\
\hline & Autumn & $389(69.84)$ & $168(30.16)$ & 1.3 & $1.02-1.7$ & 0.039 & 1.3 & $1.02-1.8$ & 0.027 \\
\hline & Winter & $404(75.51)$ & 131(24.49) & 1 & & & 1 & & \\
\hline \multirow[t]{2}{*}{ Holidays } & Holidays & $\begin{array}{c}1201(72.5 \\
2)\end{array}$ & $455(27.48)$ & 1 & & & & & \\
\hline & Non-Holidays & 292(71.05) & 119(28.95) & 1.07 & $0.85-1.4$ & 0.464 & & & \\
\hline \multirow{4}{*}{$\begin{array}{l}\text { Human- } \\
\text { caused } \\
\text { accidents }\end{array}$} & $\begin{array}{l}\text { Drowsyness } \\
\text { and } \\
\text { inattendance }\end{array}$ & 692(77.32) & 203(22.68) & 1 & & & 1 & & \\
\hline & $\begin{array}{l}\text { Left lane } \\
\text { deviation }\end{array}$ & $232(61.87)$ & $143(38.13)$ & 2.1 & $1.7-2.7$ & $<0.001$ & 2.2 & $1.7-2.9$ & $<0.001$ \\
\hline & Overspeed & $321(65.38)$ & $170(34.62)$ & 1.8 & $1.4-2.3$ & $<0.001$ & 1.9 & $1.4-2.5$ & $<0.001$ \\
\hline & Others & 285(79.39) & $74(20.61)$ & .88 & $0.65-1.2$ & 0.367 & 0.88 & $0.6-1.2$ & 0.378 \\
\hline \multirow{5}{*}{ Years } & 2013 & $234(68.02)$ & $110(31.97)$ & 1 & & & & & \\
\hline & 2014 & $333(74)$ & $117(26)$ & 0.75 & $0.6-1.02$ & 0.056 & & & \\
\hline & 2015 & $305(72.27)$ & 117(27.73) & 0.82 & $0.6-1.1$ & 0.181 & & & \\
\hline & 2016 & $389(77.03)$ & 116(22.97) & 0.63 & $0.5-0.9$ & 0.004 & & & \\
\hline & 2017 & $269(67.25)$ & 131(32.75) & 1.04 & $0.8-1.4$ & 0.764 & & & \\
\hline
\end{tabular}

Log likelihood $=-1237.7312, \mathrm{chi} 2=15.79, \mathrm{P}=0.003, \mathrm{df}=5, \mathrm{AIC}=2485.462, \mathrm{BIC}=2513.742$

\section{Discussion}

In this study, several factors, including the road type (main roads), season (autumn), overspeed, and deviation to the left lane were found out to be effective in the number of fatal accidents in the south of Kerman. The frequency of fatal accidents was higher on Tuesdays within the time interval of 08:00 pm to $12: 00 \mathrm{pm}$.
The accidents occurred on the main roads were more fatal. In a study conducted in Sistan and Baluchestan Province, most accidents occurred on main roads (8). The road type is also effective in the accident type (15). Overspeed, drowsiness, and the driver's carelessness exert a great impact on the severity of an accident (9). Overspeed increases the risk of accidents and injuries (17). Heavy traffic (18), poor lighting on sidewalks, the absence of roads, 
narrow roads, and the presence of barriers exert a significant impact on fatal road traffic accidents (19). In this study, the possibility of deaths in deviation to the left lane and overspeed was higher than that of fatigue and inattention to the front, respectively. Among human factors leading to accidents in Sistan and Baluchestan studies, the driver's carelessness has had the highest frequency (8). In a study done using the data obtained from Iran's traffic police, overspeed, fatigue, and drowsiness were the factors leading to the seriousness of drivers' errors in accidents (7). Overspeed is one of the negative behaviours that affect the health of drivers and other people (20). Overspeed, due to the possibility of a front-end accident with other vehicles and also deviation from the main lane have the highest possibility of fatal accidents (20). Overspeed exerts different effects on the occurrence of road accidents, based on road features, such as the width of the road (14). Speed limits can increase safety and reduce damage; thus, controlling the speed of vehicles, depending on the features of roads in different areas, can reduce the severity of road accidents.

The odds of fatal accidents were higher in autumn than in winter. Seasons exert a significant impact on road accidents and deaths $(9,21)$. In a study conducted in Iran, the highest and the lowest death rates were found out to be in winter and in summer, respectively (21). A study conducted in the United States showed that the severity of accidents was higher in autumn and in winter than in spring (9).

According to the studies conducted in the south of Kerman, the highest rate of mortality was in spring and in autumn (22). Another study in Rafsanjan, Iran, demonstrated that the highest and the lowest rates of accidents were in autumn and in winter, respectively (23).

Due to the cultural features and weather conditions of different regions, the probability of traveling to these regions is different in different seasons. An increase in travel rates in different periods contributes to a rise in accidents and injuries (18). The low odds of deaths in different seasons can be achieved by the low number of trips, following rules, and exercising caution (11). The high odds of accidents in autumn may be due to the start of farming activities, increased traffic, the presence of greenhouses near main roads, and the use of vehicles to transfer workers.

The highest and lowest numbers of accidents occurred on Thursdays and Saturdays of every week, respectively. In addition, the highest and lowest rates of fatal accidents occurred on Tuesdays and Sundays, respectively. Simliral to our results, in a study in US, the severity of road traffic accidents and death rate were higher in some dys of a week (9). A study in the United States showed that driving at the weekend was positively correlated with the severity of road traffic accidents and deaths (9). A study in Iran showed that road traffic accidents were varied at different times (6). It seems that a study on the large number of fatal accidents on Tuesdays and the high rate of accidents leading to injuries on Thursdays could be useful in investigating the severity of accidents on week days.

The largest number of road accidents occurred in the interval between afternoons and midnights; in addition, the largest number of accidents leading to death occurred in the time interval between 08:00 pm and 11:59 pm, and 04:00 pm and 07:59 pm. Time intervals have a great impact on the number of deaths and accidents (21). In a study in Iran, according to the data obtained from the Traffic Police, the highest rates of damage and deaths were attributed to accidents occurred at sunrise and sunset (10). According to a study in Iran, the death rate in road accidents in the interval between 1:00 am and 5:00 am was the highest (21). According to a study in the United States, driving in the evening and at night is more likely to lead to more severe accidents (9). The dark of night and the end of the day $(10,21)$, by reducing the vision of drivers and service providers, and also the drowsiness of drivers (21) exert a great impact on the number of road traffic accidents and deaths.

There were some limitations in the present study. One of the limitations was the use of the data obtained from the Traffic Police. These data could have had some recording problems. There is no doubt about the reliable recording of the data by the Traffic Police, which cannot be biased. In addition, accidents leading to deaths in car accidents were considered fatal, which might have included some of the accidents not leading to deaths. As weather conditions were the other influential factor, the lack of access to weather information was another limitation of the present study (10). It is suggested that a study be designed making use of the data from hospitals and the traffic police to investigate the effects of various factors on deaths occurred at the site of road traffic accidents and after that at hospitals.

\section{Conclusion}

In the present study, the factors contributing to the increase in the fatality rate of road traffic accidents in the south of Kerman were overspeed, deviation to the left lane, and accidents on main roads. Therefore, if the Traffic Police gives more obserations to the main roads and control vehicles' 
speed, especially in the final hours of the day, the rate of road traffic accidents may decrease.

\section{Acknowledgement}

The authors would like to express their sincere gratitude to all diligent traffic police officers of southern Kerman for the collection of the valuable road traffic data.

Conflict of interest: None declared.

\section{References}

1. Gopaul CD, Singh-Gopaul A, Sutherland JM, Rostant L, Ebi KL, Chadee DD. The epidemiology of fatal road traffic collisions in Trinidad and Tobago, West Indies (2000-2011). Glob Health Action 2016; 9:32518.

2. World Health Organization. Road traffic injuries. Fact sheet Reviewed January 2018. Geneva: World Health Organization; 2018. Available from: http://www.who.int/mediacentre/factsheets/fs35 8/en/.

3. Haagsma JA, Graetz N, Bolliger I, Naghavi M, Higashi $\mathrm{H}$, Mullany EC, et al. The global burden of injury: incidence, mortality, disability-adjusted life years and time trends from the Global Burden of Disease study 2013. Inj Prev 2016; 22(1):3-18.

4. Sadeghi-Bazargani $H$, Ayubi E, Azami-Aghdash S, Abedi L, Zemestani A, Amanati L, et al. Epidemiological patterns of road traffic crashes during the last two decades in Iran: a review of the literature from 1996 to 2014. Arch Trauma Res 2016; 5(3):e32985.

5. Forouzanfar MH, Sepanlou SG, Shahraz S, Dicker D, Naghavi P, Pourmalek F, et al. Evaluating causes of death and morbidity in Iran, global burden of diseases, injuries, and risk factors study 2010. Arch Iran Med 2014; 17(5):304-20.

6. World Health Organization. Global status report on road safety 2015. Violence and Injury Prevention. Geneva: World Health Organization; 2018. Available from:

http://www.who.int/violence_injury_prevention/r oad_safety_status/2015/en/.

7. Moafian G, Aghabeigi MR, Heydari ST, Hoseinzadeh A, Lankarani KB, Sarikhani Y. An epidemiologic survey of road traffic accidents in Iran: analysis of driver-related factors. Chin $\mathrm{J}$ Traumatol 2013; 16(3):140-4.

8. Rad M, Martiniuk AL, Ansari-Moghaddam A, Mohammadi M, Rashedi F, Ghasemi A. The pattern of road traffic crashes in South East Iran. Glob J Health Sci 2016; 8(9):51677.

9. Feng $\mathrm{S}, \mathrm{Li} Z, \mathrm{Ci} Y$, Zhang $\mathrm{G}$. Risk factors affecting fatal bus accident severity: Their impact on different types of bus drivers. Accid Anal Prev 2016; 86:29-39.

10. Lankarani KB, Heydari ST, Aghabeigi MR,
Moafian G, Hoseinzadeh A, Vossoughi M. The impact of environmental factors on traffic accidents in Iran. J Inj Violence Res 2014; 6(2):64-71.

11. Liu A, Soneja SI, Jiang C, Huang C, Kerns T, Beck $\mathrm{K}$, et al. Frequency of extreme weather events and increased risk of motor vehicle collision in Maryland. Sci Total Environ 2017; 580:550-5.

12. Goh K, Currie G, Sarvi M, Logan D. Factors affecting the probability of bus drivers being atfault in bus-involved accidents. Accid Anal Prev 2014; 66:20-6.

13. Saha S, Schramm P, Nolan A, Hess J. Adverse weather conditions and fatal motor vehicle crashes in the United States, 1994-2012. Environ Health 2016; 15(1):104.

14. Aarts $L$, van Schagen I. Driving speed and the risk of road crashes: a review. Accid Anal Prev 2006; 38(2):215-24.

15. Statistical Center of Iran. Results of the 2016 National Population and Housing Census [Internet]. 2016 [cited 5 May 2018]. Available from: https://www.amar.org.ir/english/Statisticsby-Topic/Population\#2224493-releases

16. Philip P, Chaufton C, Orriols L, Lagarde E, Amoros E, Laumon B, et al. Complaints of poor sleep and risk of traffic accidents: a populationbased case-control study. PLoS One 2014; 9(12):e114102.

17. Brenac T, Perrin Ch, Canu B, Magnin J, Canu A. Influence of travelling speed on the risk of injury accident: a matched case-control study. Periodica Polytechnica Transportation Engineering 2015; 43(3):129-37.

18. Mirzaei M, Mirzadeh M, Shoqaei Far H, Mirzaei $M$. Trends in road traffic deaths in Yazd, Iran, 2004-2010. Arch Trauma Res 2016; 5(2):e29266.

19. Bakhtiyari $M$, Soori $H$. Epidemiology of traffic crashes outcomes and related factors in Iran. Journal of Safety Promotion and Injury Prevention 2013; 1(3):150-9.

20. Hassan HM, Shawky M, Kishta M, Garib AM, AlHarthei HA. Investigation of drivers' behavior towards speeds using crash data and selfreported questionnaire. Accid Anal Prev 2017; 98:348-58.

21. Mehmandar M, Soori H, Amiri M, Norouzirad R, Khabzkhoob M. Risk factors for fatal and nonfatal road crashes in Iran. Iran Red Crescent Med J 2014; 16(8):e10016.

22. Nasiri N, Vazirinejad R, Rezaeian M, Sharifi $H$, Sanji Rafsanjani M. Epidemiology of mortality among road accident victims in the south of Kerman Province, Iran, from 2012 to 2015. Journal of Occupational Health and Epidemiology 2017; 6(3):136-43.

23. Taravatmanesh L, Mortazavi SM, Baneshi MR, Poor MS, Saeedifar A, Zolala F. Epidemiology of road traffic accidents in Rafsanjan city, Iran. Electron Physician 2018; 10(5):6859-63. 